\title{
Fast-tracking Research Methodology Immersion for Students: Experiences from a Project on Fairwork in the Gig Economy
}

\author{
Marita Turpin ${ }^{1}$ and Jean-Paul Van Belle ${ }^{2}$ \\ ${ }^{1}$ Department of Informatics, University of Pretoria, South Africa \\ ${ }^{2}$ Centre for IT and National Development in Africa, University of Cape Town, South Africa \\ Marita.Turpin@up.ac.za \\ Jean-Paul.VanBelle@uct.ac.za
}

\begin{abstract}
This paper showcases an innovative student research project in a South African taught Masters programme, where students learnt to apply a sound research methodology in the real world, and align their work with a global research project. The Fairwork (https://fair.work) project assesses the extent to which gig work platforms in a number of countries conform to 'fair work' principles for their workers. The Fairwork project has a clearly defined and rigorous research methodology used by senior academics around the world to rate labour-broking platforms such as those in e-hailing (Bolt, Uber) or delivery services (UberEats) to rate their adoption of fair work principles for their workers. The University of Pretoria adopted this research methodology in the context of a student-based group project in a taught 2020 "Digital Economy" Masters programme. Student groups used the same methodology and interviewed South African platform workers to score seven different platforms. The key motivations and intended benefits were that the research methodology was already tried and tested, students should able to apply the skills taught in an earlier (theoretical) research methods course, subject specific knowledge around the gig economy had to be researched and was internalized, each group had the freedom to select its own platform, results could be validated against publicly available ratings, students engaged themselves in real world empirical research, and their research outputs had a real world relevance. In addition, this project turned out to work well under Covid19 partial lockdown circumstances. The student submissions exceeded the expectations of everyone involved, and some groups produced research results which matched the level of highly experienced researchers. This project also provides a strong contribution to the academic community, not only because it provides a validation benchmark and alternative research approach to the Fairwork project, but also because this project is easily portable to similar courses in other country contexts.
\end{abstract}

Keywords: teaching research methods; research methods education; project-based learning; active learning; authentic learning; fair work principles

\section{Introduction}

Teaching research methodology in the social sciences is challenging, partly because research methods are a complex domain (Strangman and Knowles, 2012; Saeed and Al Qunayeer, 2021), even more so in contexts where educator resources are scarce relative to the number of students and the student body is diverse in educational background and preparedness (Longmore, Dunn and Jarboe, 1996). Most importantly, the educational value of "learning by doing" i.e. project-based research, has proven to be best way to way for students to improve their performance and enhance their learning experience (Aguado, 2009; Earley, 2014; De Lima, 2021).

This paper presents a model adopted in a post-graduate masters student cohort of 35 part-time, professionals that combines the benefits of active learning, problem-based learning, cooperative (or group) learning, service learning and 'learning by doing', all the while by being embedded in a full online learning environment forced on the group by Covid-19 lockdown. Students not only apply a sound research methodology in the real world but align what they're doing with a global research project. The project used was the Fairwork (https://fair.work) project, that seeks to assess to what extent selected "fair work" principles are adhered to by gig work platforms by research teams in almost 20 countries around the world, including UK, Germany, India and South Africa. This project has a clearly defined research methodology developed and used by senior academics, research fellows and postdoctoral students around the world to rate labour-broking platforms such as those in e-hailing (Uber) or delivery services (UberEats) on their adoption of fair work principles for their workers. The University of Pretoria decided to see if this methodology could be adopted in the context of a student-based group project in a taught 2020 "Digital Economy" Masters programme. Student groups used the same methodology and interviewed South African platform workers to score seven different platforms.

The key motivations and intended benefits were that the research methodology was already tried and tested, students were able to apply the skills taught in an earlier (theoretical) research methods course, subject specific 
knowledge around the gig economy had to be researched and was internalized, each group had the freedom to select its own platform, results could be validated against publicly available ratings, students engaged themselves in real world empirical research, and their research outputs had a real world relevance.

The approach is easily replicable, and especially suited to remote teaching environments (Covid-19!), larger class sizes (30-60 students) and lecturer-resource constrained environments as is typical in the Global South. In addition, the student learning and experiential outcomes are arguably better than those of a traditional lecturerdriven course offering. We are convinced that this approach could be adopted quickly and easily by other lecturers seeking to integrate research methodology in a subject-specific domain and achieve a win-win situation by reducing lecturer workload and increasing student satisfaction and learning.

\section{Literature review}

Earley (2014) provides an encompassing synthesis of the literature on research methods education, based on 89 studies. He looks at the typical student profile in a research methods course, noting the issues of student perceptions of (ir)relevance, anxiousness and misconceptions about research. He also provides an in-depth pedagogical assessment of the different types of creative teaching modalities to make research courses more effective and interesting, including active learning, problem-based learning, cooperative (or group) learning, service learning and on-line learning, concluding that "there is a need for this sort of research to continue. The benefits of discussing [...] how we teach and assess, and what content we teach in these courses has far-reaching consequences for improving the educational experience of countless students" (Earley, 2014, p 249).

For students to develop real competence in research methods, they have to gain practical experience of the research process that is as realistic as possible (Burgess, 1990). Although theoretical lectures are necessary, real understanding and consolidation comes from 'learning by doing'. Students need exposure to real-life contexts as "research is not only a technical process" (as depicted in textbooks) "but also a situational, personal and political process" (Bækgaard and Lystbæk, 2019, p 334). Bækgaard and Lystbæk (2019) further urge that students should be given the chance to descend into the swampy lowlands of real-life messy practical contexts, which is where the best learning takes place.

Where research methodology courses embed a practical component, typically the common approaches are located at one of two opposite extremes of the spectrum. At the one extreme, students are given isolated exercises at the end of each module e.g. determining the sample size for a particular study; at the other extreme individual students are tasked with executing up an entire research project from beginning to end, in effect writing up a thesis or research article by themselves (Tashakkori and Teddlie, 2003). However, letting student groups replicate a significant but relevant portion of a real-world ongoing research project can in some ways be the best of all words: the individual student load is limited, students learn from best practices, they go through the entire research life cycle in just a few weeks, this model can be used for medium-sized classes where student numbers are between 30 and 60, students experience the messiness and trade-offs of real-world research, less experienced students can get support from more experienced or knowledgeable peers, they have a basis for comparison and evaluation of their own findings, and they feel that they can make a meaningful contribution at the level of professional researchers. This literature review looks at supporting evidence for this model.

An early study demonstrated the value of teaching research methods by letting students participate in a commissioned research project (Winn, 1995). This case study described the value and motivational aspects provided by letting students participate in a real-world project instead of an artificially created exercise or a student-generated one. As she puts it: "Teaching research methods to social science [students] presents a number of dilemmas, including the development of effective means of providing students with practical research experience and the difficulty of engaging the interest of students in a subject which for many is not intrinsically appealing and to which some have a long-standing aversion. One way of addressing these issues is to enable students to participate in a 'real' research project" (Winn, 1995, p203).

Longmore, Dunn and Jarboe (1996) focus on the practical and organisational benefits of group research projects, especially where the class sizes go beyond the small classes e.g., 30+. At that stage, asking students to engage in practical research experience is often limited by the lecturer resources required to plan, coordinate, guide or evaluate the student work. Gitanjali and Raveendran (1998) similarly points out the benefits of a group research project over individual student work, although a reduced workload on staff cannot be taken for granted (Panelli 
and Welch, 2005). Group-based work can assist in this, but only when the group project has been carefully designed; for which they make several experience-based practical suggestions.

However, a project-driven approach should not just be driven by pragmatic resource considerations; in the end, pedagogical considerations such as the student learning and experience should be the key decision criterion for curriculum design (Wagner, Garner and Kawulich, 2011). A study at master's level social science found groupwork to have a positive effect on learning experience, as well as performance (Barraket, 2005). This study was interesting because this particular course aligned very well with the context of our circumstances: it was also mainly composed of full time employed professionals in their field and, although it was a relatively small course (only 23 students) it had students from very diverse backgrounds. This study emphasizes that active learning through group work represents a move towards student-centred learning, and can be seen as an enactment of constructivist learning theory.

The student-centred, project-based model does not just require the students to be engaged with the actual execution of the research, but students should have a relative autonomy in the project planning and management, and the presentation of their own findings before the entire class is an important component to avoid the passive lecture format: The "[project should] involve students in design, problem-solving, decision making, or investigative activities, provide students the opportunity to work relatively autonomously over extended periods of time; and culminate in realistic products or presentations. Other features include authentic content, teacher facilitation but not direction, and explicit educational goals" (Braguglia and Jackson, 2012, p.348).

The additional advantage of a group project is that students tend to divide the tasks internally according to their skills sets and experiences, thus enabling the group as a whole to benefit maximally from their internal strengths: "When project groups divide tasks at each stage of the project, they can do a more thorough job and produce a more professional report" (Longmore, Dunn and Jarboe, 1996, p87). Additionally, 'real' or 'hands-on' field practice, especially in a group learning approach, increases student satisfaction and enhances the student experience (Panelli and Welch, 2005). These benefits of an 'active learning' approach were also borne out in another master's course where students reported that, through the project, "involvement was meaningful, promoted understanding of research, strengthened relations among students, and made learning more exciting" (Lundahl, 2008, p. 273).

Interestingly, Panelli and Welch (2005) used a categorizing framework (Kent et al., 1997) with the dimensions of autonomy versus dependency, and observation versus participation, to classify field-based research as being most desirable (high on autonomy and participation). However, they also point out the potential issues of group study including the potential for disharmony/personality clashes, uncertainty around the group assessment, unequal inputs by the different student members and that staff workload is often not reduced.

Finally, the Covid-19 pandemic presented lecturers in 2020 with an additional challenge: traditional classroom presentations had to give way in many cases to a blended or even purely online environment because campuses were closed due to lockdown situations. Teaching research methods in an internet-based blended-learning setting presents even more challenges in terms of student motivation, anxiety and the amount of learnerinstructor interface time that can be accommodated (Schober et al., 2006). This, again, is an added rationale for, and benefit of, a student-centred group research project.

The next section introduces the global study on which the student group project was based.

\section{Using a global research project as model: The Fairwork Project}

Digitisation - in particular, growth in broadband access and online platforms - is enabling the emergence of new forms of work and income generation that challenge our common understanding of work and employment. This new platform economy (also termed the digital gig economy, sharing economy, uberisation, etc.) is already employing tens of millions in the global South (Heeks et al., 2020). Its size and rapid growth mean it forms an important constituent of the future of work, and it has been embraced by governments, development agencies, social enterprises and others as a key means of addressing the high levels of unemployment in the global South. While delivering livelihood benefits to workers, platform work has also been evidenced as falling far short of ILO decent work standards (Heeks 2017). While the platform economy has widened access to work for some, it is 
also circumventing the rights and standards associated with employment by denying the status of "worker" to those who supply their labour (Galperin and Alarcon 2017). Unless action is taken, this insecure, "unfair" work will become the new norm for growing numbers of workers (and especially vulnerable workers) in the South (Graham et al., 2020).

The global Fairwork project (https://fair.work) attempts to evaluate and improve the working conditions of digital platform workers by rating digital gig economy platforms on their adherence to a subset of decent or fair work standards. "Drawing inspiration from the Fairtrade and Living Wage campaigns, it aims to create pressure on platforms to improve working conditions through a public ranking system which scores selected platforms according to their record under five broad principles: fair pay, fair conditions, fair contract, fair management and fair representation" (Graham et al., 2020, p.237).

By end 2020, the Fairwork project had assessed and rated platforms in Germany, South Africa, India, Chile and Ecuador, with some platforms in the former three countries already adopting changes in response to the published ratings. The South African pilot of the Fairwork project was initiated in 2018 with the first round of data collection and rating was done in early 2019 for 10 platforms (Fairwork, 2019). In the meanwhile, data for a second year was collected on an extended selection of platforms with the results being released early in 2020 (Fairwork, 2020).

The methodology for the empirical component of the Fairwork project is aimed at obtaining defensible data for rating each platform according to the five principles or 'pillars' of fair work: fair pay, fair working conditions, fair contracts, fair management and fair worker representation (Graham et al., 2020; Heeks et al., 2021). Figure 1 shows the principles used in evaluating a given platform and a sample score for a South African platform (Howson et al., 2020).

The first step is the platform selection: choosing which platforms are to be rated. Three guiding criteria are to find the platforms with the most workers, to include platforms that have been rated in previous rounds and, ideally, to have at least two representative platforms in any given sector (e.g. e-hailing). The empirical data collection consisted of three sources. Firstly, desk research was used not only to select the platforms but also to collect whatever pertinent data could be useful such as ongoing disputes, extra worker benefits or online contracts. A second source of information was platform owner or manager engagement. Meetings with platforms were sought to inform them about the project, request any data that was pertinent but also later to build up a dialogue around further engagement e.g., suggesting how to improve their scores. In some cases, platforms elected not to engage, and a number of platforms just communicated via email or electronic meetings.

The third and most resource intensive method is interviewing platforms directly with a target sample of 6 to 10 workers per platform. Although this cannot be seen as 'representative samples', especially not for earnings or communications, the interviews were not intended to be that. They allowed for the scoring of most of the principles (e.g., only one example of a contract is needed) or for negative data (if two out of five workers are paid below the threshold). This data is pulled together, and only positive evidence used towards awarding the final scores. A 0 score either indicates negative evidence (i.e. the platform does not comply with the principle) or a lack of data. When provisional scores have been awarded, they go through an internal peer-review process.

Provisional scores are communicated to each platform, who are then invited again to provide the researchers with missing or correcting information prior the final release of ratings. Figure 2 shows the 2020 scores for the 11 South African platforms. The seven groups of the MIT845 selected one of these platforms each and compared their scores/ratings to the official 'Fairwork' rating. 


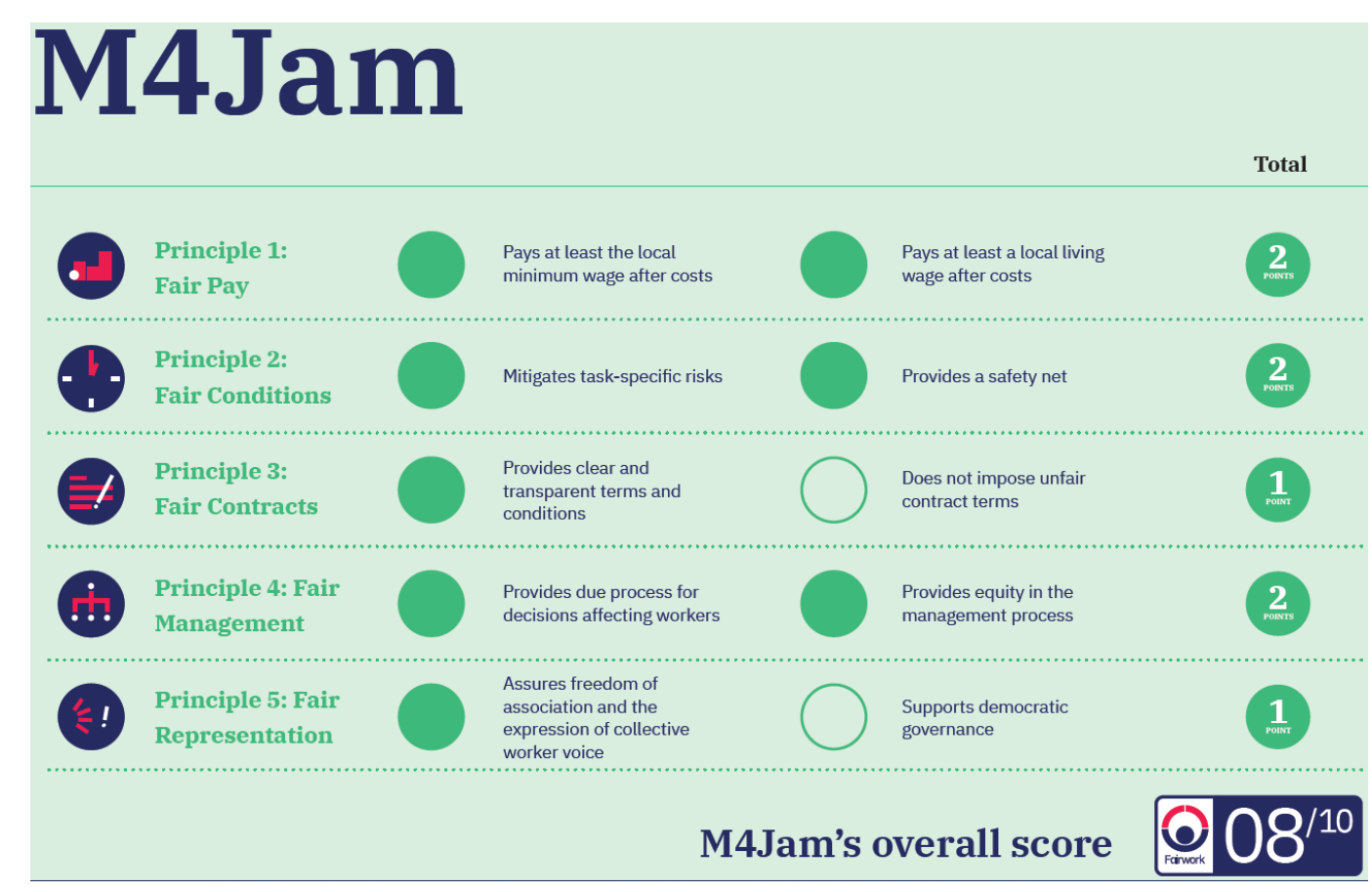

Figure 1: Sample score calculation for M4Jam, a South African mobile cloud work gig platform (Fairwork, 2021a)

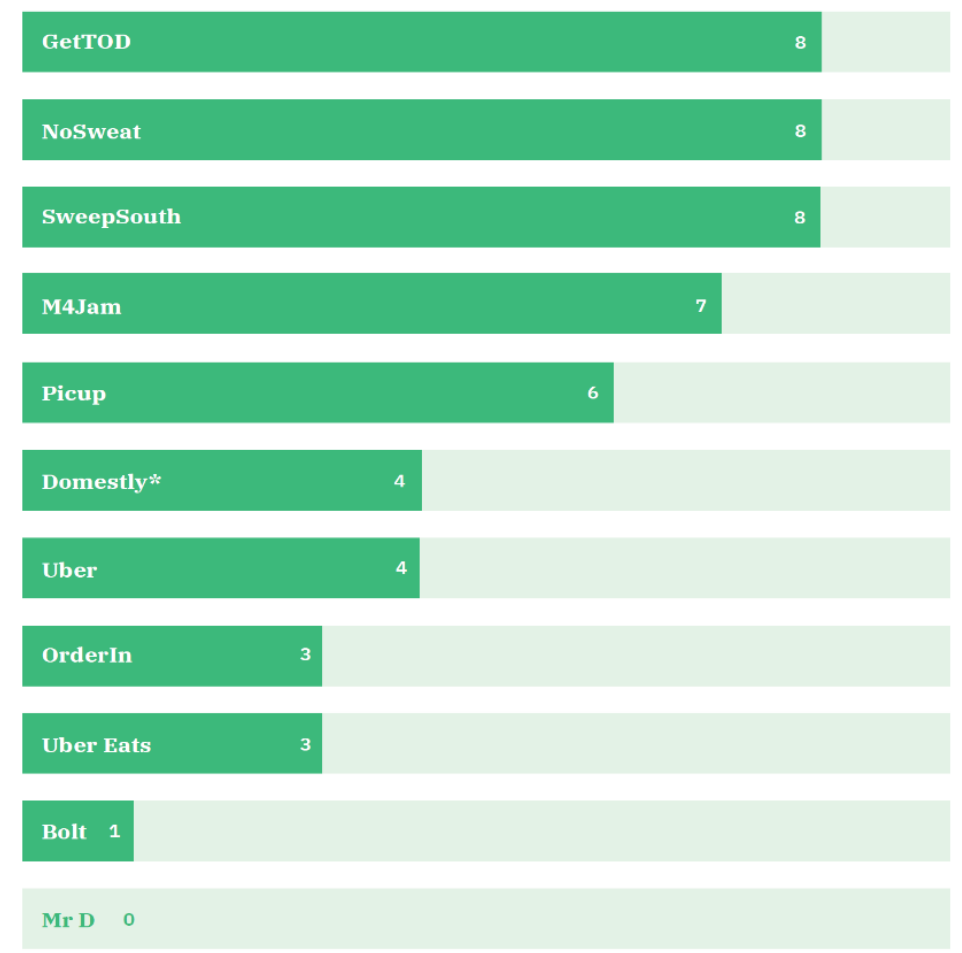

Figure 2: The official 2020 Fairwork ratings for South African platforms (Howson et al., 2020)

\section{The MIT845 student research group project}

The MIT845 course is part of a taught Master's in Information Technology (MIT) degree programme, where half of the degree is coursework and the other half is a mini-dissertation. The degree is informally referred to as an "IT MBA", equipping students for the management and leadership of IT- related initiatives in organisations. Students are selected to enrol for the degree if they possess relevant qualifications and work experience. Since it is a selection programme, the calibre of students in the class is relatively high. One of the first courses presented as part of the MIT programme is research methodology, which introduces students to research methods from the management and social sciences that are applicable to the IT field, as preparation for their 
mini-dissertation. The research methods course is theoretical and does not allow space for application or empirical work. Hence, at the onset of the MIT845 course, students have book knowledge of research, and may have had previous exposure to executing research but this is not a given.

The 'MIT845 Digital economy' course aims to provide students with the tools, skills and an understanding of the technology, business concepts and issues surrounding the emergence of the digital economy. Key topics in the course are the digital economy, the platform economy and the disruptive technologies of the Fourth Industrial Revolution (4IR). Apart from understanding these topics at concept level, students need to understand the opportunities and implications they hold in a South African business context. In addition, students need to understand the opportunities and challenges of the digital economy, platform economy and the 4IR in a developing country context.

In the previous years that the course was presented, it was found that students benefited from having a larger, challenging group project where they had to apply and integrate their theoretical skills and pool the diversity of their capabilities to produce an innovative set of deliverables. The idea of basing their 2020 group assignment on the international Fairwork project, arose when the students of 2019 responded very enthusiastically to an invited guest lecture on the Fairwork project. A Fairwork related applied research project would not only allow for the application of theoretical knowledge gained on the MIT845 course, it would also allow students to apply the skills learnt during their research methodology course. In addition, practically engaging with the fair work principles would be very relevant in the South African developing country context. A Fairwork inspired group assignment was therefore formulated with the involvement of a colleague from the South African Fairwork team. The student project was however ring fenced from the 'real' Fairwork project, to allow for a learning opportunity with no reputational implications to the actual Fairwork project. The group assignment instructions are detailed in the remainder of this section.

This group assignment focussed on South African-based digital labour-broking platforms and the extent to which they adopt 'fair work' principles for their workers. Each student group first did a desktop (literature) research on the platform economy, fair work and then adopted one specific platform to further investigate their selected platform's current status in the South African economy, conduct some minimal empirical research using a prescribed research methodology by interviewing workers in terms of their experiences, specifically relating to the fair work principles and synthesize their findings -partly comparing them to prior ratings accorded to the platform.

The assignment objectives were to let the student research the platform economy in-depth using both local and global perspectives; to understand how platforms change the nature of work and necessitate new conceptualizations around work, ethics and the social contract; to experience empirical field research using a standardized research methodology and interview protocol; to analyse interview data and write up a structure summary report.

Each group consisted of about 5 students. These groups were self-selected and then they chose their own unique platform (i.e. only one group chose Uber, one group chose Bolt etc.) Preference was to be given to 'locationbased' platforms i.e. where the work provided by the worker requires the worker to be specifically present and 'in location' (e-hailing, domestic, services rendered etc.) although a 'cloud-based' platform could also be selected i.e. where the work provided is of a digital nature and location of the worker pretty immaterial. After doing desk research on the platform economy in general, and one pre-selected platform in particular, this group then looks at the Fairwork Foundation's (https://fair.work) principles for decent platform work - which incorporate ILO decent work standards - by assessing to what extent these principles are adhered to by local digital platforms in South Africa. Empirical data had to be gathered from workers on a selection of local platforms using semistructured interviews but using the formal Fairwork methodology and suggested interview protocol. The groups did both a class presentation (using e-meeting software) and submitted a final report under the following headings:

- Brief description of the platform type (e.g. "e-hailing") and specific platform (e.g. "Uber" globally and South Africa)

- A critical academic literature review on the socio-economic impact of the given platform type (e.g. ehailing) and the platform itself to the South African economy from a micro- and macro perspective.

- A concrete Fairwork rating: to what extent does the platform adhere to the fairwork principles - award a $x / 10$ score using a table format with detailed motivation in the form of substantive quotes (or other 
evidence). This rating was compared to the latest 'official Fairwork' rating the platform achieved with possible explanations of deviations.

- A qualitative assessment of how workers actually experience their work (subjectively) adding in both positive and negative aspects and experiences. This section gave students an opportunity to be critical.

- References

- Appendices: interview transcriptions.

Before commencing the group project, the MIT845 students received an individual assignment where they had to read literature and answer questions on the theory and constructs underlying the digital and platform economies, as well as on the Fairwork initiative. They also received a guest lecture on the Fairwork project. Because of this, all students entered the group project with a contextual orientation.

\section{The group project outcomes}

In this section, we discuss how the students presented their group assignments and, based on a feedback survey, how the students experienced their projects.

\subsection{Student deliverables}

The seven student groups had to present their projects by means of an online presentation as well as a final report. Online presentations were done on the e-meeting platform that formed part of the university's Learning Management System (LMS). Except for a small number of connectivity and technical challenges, the presentations went smoothly, with lively participation (in the form of chat box comments) by the rest of the class. This is seen as a major achievement, as 2020 was the first year that all contact sessions had to be conducted fully online. The lively class interaction, which contained a large amount of humour, was seen as a particular bonus, since constructive class interaction and participation was historically one of the highlights of the MIT contact sessions. The presentations were of a very high professional calibre, and students took effort to summarise the considerable amount of work they performed to stay within the allocated time slots.

In addition to impacting the class presentation format, the lockdown restrictions also presented challenges to the students in terms of group meetings and empirical data collection. However, all groups successfully rose to the challenge of finding mutually suitable means to conduct group meetings and field work.

The assessment of the presentations and final reports were jointly done by the lecturer and expert guest lecturer. As with the presentations, the final reports were mostly of a very high quality. Five of the seven groups received distinctions despite high marking standards. By and large, the class exceeded the lecturers' expectations in terms of the enthusiasm and positive attitude with which they completed the projects despite various practical challenges. Lecturer expectations were also exceeded in terms of the professional manner that the groups executed their projects, leading to overall high-quality deliverables.

\subsection{Student learnings}

At the end of the MIT845 course, a feedback survey was released to the students, with the aim of getting feedback on the Fairwork inspired group assignment. The survey included open ended questions inviting feedback on what students found most valuable of the assignment, least valuable, most challenging, suggestions for improvement as well as general feedback.

Feedback was largely positive/complimentary, in line with the positive spirit that was experienced during contact sessions. Under the question of what students found most valuable, gaining research experience emerged as a strong theme:

"Interviews and data analysis... that served as a warmup to my research next year"; "When you ask open ended questions you get more detailed information. I was able to gain experience on conducting interviews"; "Having real world interviews and discussions"; First time experience conducting an interview"; "Analysing the data was awesome". Interestingly, various aspects related to data collection and analysis also featured strongly under the most difficult or challenging aspect of the assignment, with responses such as: "Getting willing participants was a challenge"; "Getting participants to agree to interviews and feel comfortable"; "Having to interview ... face to face"; "We really struggled with the interviews..." "Gaining the trust of the respondents and making them feel comfortable ... participating in the research"; "Getting information from some of the participants and those that were very open to 
answering questions sometimes struggled with understanding the question, so ... finding a different way of asking the question without losing the essence of the question was tricky"; "Data analysis and writeup".

A second theme that strongly emerged under the most valuable aspect of the assignment, was the learning that took place around the working conditions of platform workers: "Learning about the real working conditions of various platform workers"; "Learning about the platforms and how the workers are treated. We often only think of ourselves when using this platform and neglect to understand that the worker could be neglected or ill-treated by both customer and owner/producers"; "Getting to understand the lives that others on the other side are living and the challenges they are facing, instead of ordering something and having it delivered by someone and not thinking any further. I am now inspired to use services in the future that have better Fairwork Ratings."

Under the question of the least valuable aspect of the assignment, most students had nothing to comment. Similarly, there were not many suggestions for improvement, however a few students suggested receiving more time to complete the assignment.

Interestingly, a handful of students voiced their frustration with learning about the challenges of the platform workers without being able to improve the workers' situation: "Once we had interviewed these people, there is no clear next steps for the drivers. we leave them in the same situation, there is no continuation in helping resolving some of the issues they face."; "Not having tangible solutions to the problems that the interviewees raised"; "Interviewees wanted to know if their feedback would make a difference". These comments speak to the research ethics of descriptive research, where the researcher enquires about people's problems without being able to help them. Students were warned upfront that workers' expectations should not be raised as a result of the interviews. However, this is a general dilemma of empirical research that the students were exposed to.

Under general feedback or comments, the following feedback was received: "Great exercise"; "The experience was eye opening and I earnt a lot from it"; "Great assignment, liked the practicality in it". From these comments it is clear that the practical exposure that the students received was regarded as valuable to them.

One of the concerns carried by the lecturers were the practicality of executing this assignment under the Covid19 lockdown restrictions in South Africa, both in terms of executing groupwork and doing data collection. However, only a small number of students mentioned lockdown as a constraint, with comments such as the following: "Due to lock down the aspect of being able to meet and discuss findings as a group but this is the new normal and online discussions are also effective." "Working in groups was not easy as we had to do everything online" "Doing it under lockdown came with many challenges." Overall, lockdown challenges did not emerge as a strong theme in the student feedback and did not seem to prevent the groups from doing good work. As the one student remarked, having to meet online has indeed become the 'new normal' across all aspects of people's lives; it was a general everyday challenge and not limited to this assignment specifically. As mentioned in section 5.1 , all groups successfully rose to the challenge of meeting online, collecting data under lockdown restrictions and presenting their findings online.

\section{Critical reflection on lessons learnt and contribution}

\subsection{Benefits for students}

From the student feedback received, two main areas of learning emerged. The first was the value that students gained from performing 'real life' interviews and data analysis - something they simultaneously reported as most challenging and most valuable. This finding is consistent with the research of Aguado (2009), Earley (2014) and De Lima (2021) who found that "learning by doing" is the best way for students to gain knowledge.

The second area of learning, was about the working conditions of platform workers, where several students attested to the project being an eye opener for them, and that they started thinking differently about using the services of a platform business. This finding aligns with the results of Lundahl's (2008) study, where students experienced the real-world involvement as meaningful. It further confirms that "research is not only a technical process, but also a situational, personal and political process" (Bækgaard and Lystbæk, 2019, p 334). 
It is therefore evident that this project, which simultaneously allowed for active learning, problem-based learning, cooperative (or group) learning, service learning and on-line learning, as advocated by Earley (2014), complied with the ideals of the effective teaching of research methods discussed in Section 2.

\subsection{Contribution to the Global Fairwork Project}

During the assessment of the group projects, a significant portion of the marks were awarded to the rating of the platforms, including the motivation for the rating score. Because of the high quality of the work performed by the students, their ratings had potential practical significance beyond just the education aims of the group project. It was found that these outputs could be used to validate the ratings exercises performed by the professional Fairwork team. One of the aims of the 2020 group project was to see whether university Masters students were able to deliver work of a calibre that could in future contribute to the Fairwork project, and this aim was achieved. Therefore, in addition to the academic contribution of the project to the students' learning, the project had potential practical value, to be replicated in other developing country contexts, which could add a multiplier effect to the current Fairwork initiative and its global impact. In particular, these student projects could also serve as pilots in countries (or country regions) where currently no dedicated Fairwork researchers are active. Thus, this project presents an example of how a student project can be used to align with a real-world ongoing research project in the social sciences, as advocated by Winn (1995), to not only enhance student learning but also make a practical research contribution.

\subsection{Success factors}

A number of factors are believed to have contributed to the success of the group project. Firstly, students were equipped with sufficient domain knowledge on the topic at hand during the course, as well as a more theoretical knowledge of research methods in a prior module. Indeed, the project served as a real-world illustration of the curriculum content of the module allowing for a two-way benefit: it deepened the students' understanding of the theoretical curriculum content, but the theoretical readings informed the practical work. Secondly, in the context of the Covid-19 restrictions moving the course online, it was vital that the assignment instructions were comprehensive and clearly communicated. Furthermore, the students had an appropriate level of capability to execute the project by virtue of being mature Masters students who went through a rigorous selection process. Most importantly, the scope of the project was realistic in terms of i.e. a ten-week period was allowed for, and each student had only one or two interviews to conduct. The financial costs associated with procuring or engaging a very few gig workers is relatively small. Luckily, interviews could be conducted not only face-to-face but also using electronic channels e.g. WhatsApp. But, importantly, the project proved to be non-trivial i.e. it was intellectually as well as practically challenging, providing students with sufficient motivation to produce quality work. Finally, lecturer guidance was available throughout.

\subsection{Replicability in terms of potential extension to other contexts or projects}

The logical but important question is whether a student group research project is replicable to other contexts namely other domains or other countries. Firstly, it must also be noted that the Fairwork project is currently being conducted in more than twenty countries around the globe, successfully using the same methodology and same principles; and the number of participating countries is increasing fast. Thus, academics around the world should feel comfortable adopting the project as described above, i.e. using the Fairwork methodology as it stands, in their own home country. If one's country has insufficient location-based gig work platforms, one could also consider using the global cloudworking platforms instead, although these have slightly different versions of the principles (Fairwork, 2021b). A first step would be to liaise with their local country Fairwork research team who would, no doubt, be very glad to assist with the work. However, an official affiliation with the Fairwork project, given the difficulty in quality controlling student work, may be more difficult to pursue.

However, it is the authors' belief that, if most of the success factors listed in 6.3 are in place, there should be no reason why the student research project has to be modelled on the Fairwork research. Indeed, any global research project with an explicitly articulated research methodology, a clear and useful scope, and requiring empirical evidence that can be gathered from multiple independent and relatively small sub-samples (one per group), is suitable for this type of student group-based research approach. Indeed, the methodology could require quantitative (survey-based) or qualitative (interview or focus-group based) data collection, and required analysis methods could range the gamut of available statistical or qualitative methods. In either case, the authors will be pleased to share any materials such as assignment, background readings, methodology details and presentation slides. 


\section{Conclusion}

This paper reported on an innovative student research project in a South African taught MIT programme, where students applied a sound research methodology in the real world and were able to align what they were doing with a global research project. The project had the unplanned constraint of having to be executed during a national Covid-19 lockdown, where all teaching and learning occurred online, and students had to present their work online. The class consisted of 35 full-time professionals divided into seven groups. Each group chose a different South African platform company on which they had to perform a fair work rating by means of interviewing platform workers. The student work generally exceeded expectations, with some of the deliverables at the level of experienced researchers. The group project allowed the students to practically apply the research methods they were taught in a preceding course in a real-world context, while simultaneously engaging with a socially relevant platform economy topic. Students found the interviews and data analysis to be the most challenging as well as one of the most useful aspects of the project. They also admitted that engaging with platform workers was an eye-opener to them and changed their perspectives on platform companies and the working conditions of platform workers.

This study contributed by showcasing how a student project can be used to align with a real-world ongoing research project in the social sciences, not only to enhance student learning but also making a practical research contribution. Future research could entail replicating this study in different countries and universities as part of the global Fairwork initiative. In fact, projects like these could be seen as a first step to increase the global coverage of the Fairwork research to countries or areas where there are insufficient full-time research resources. Most importantly, the model of basing and aligning a student group-based research project with an existing global research project is not limited to the Fairwork project; any global research project with similar modalities (i.e. those having a clear, explicit research methodology and requiring multiple sets of relatively small but focussed empirical sub-samples) could be used as a model. However, it is important to ensure that some critical success factors, as listed in section 6.3, are in place. Hopefully this linking of rigorous academic research with student research projects and real-world engagement will be explored in many other contexts.

\section{References}

Aguado, N. A. 2009. Teaching Research Methods: Learning by Doing. Journal of Public Affairs Education, 15, pp 251-260.

Bækgaard, L. and Lystbæk, C.T., 2019. Learning to Do Knowledge Work: A Framework for Teaching Research Design in Engineering Education. International Journal of Engineering Education, 35(1), pp.333-344.

Barraket, J., 2005. Teaching Research Method Using a Student-Centred Approach? Critical Reflections on Practice. Journal of University Teaching and Learning Practice, 2(2), p 3.

Braguglia, K.H. and Jackson, K.A., 2012. Teaching research methodology using a project-based three course sequence critical reflections on practice. American Journal of Business Education (AJBE), 5(3), pp 347-352.

Burgess, R.G., 1990. Sociologists, training and research. Sociology, 24, pp 579-595.

De Lima, J.Á., 2021. Authentic learning in the undergraduate social research methods classroom: students' perspectives on project-based pedagogy. SN Social Sciences, 1(1), pp1-23.

Earley, M.A., 2014. A synthesis of the literature on research methods education. Teaching in Higher Education, 19(3), pp 242-253.

Fairwork, 2019. The Five Pillars of Fairwork: Labour Standards in the Platform Economy. Oxford, UK; Manchester, UK; Cape Town, South Africa; Bangalore, India. Available at: <https://fair.work/wpcontent/uploads/sites/97/2019/10/Fairwork-Y1-Report.pdf> [Accessed 4 September 2021].

Fairwork, 2020a. Gig Workers, Platforms and Government During Covid-19 in South Africa. Oxford, United Kingdom, Available at: <http://fair.work/wp-content/uploads/sites/97/2020/05/Covid19-SA-Report-Final.pdf> [Accessed 4 September 2021].

Fairwork, 2020b. Fairwork 2020 Annual Report, Oxford, United Kingdom.

Fairwork, 2021a. Fairwork South Africa Ratings 2021: Labour Standards in the Gig Economy. Cape Town, South Africa; Oxford, United Kingdom. Available at: <https://fair.work/wp-content/uploads/sites/131/2021/07/Fairwork-SouthAfrica-2021-report.pdf> [Accessed 4 September 2021].

Fairwork, 2021b. Work in the Planetary Labour Market: Fairwork Cloudwork Ratings 2021. Oxford, United Kingdom. Available at: <https://fair.work/en/fw/publications/work-in-the-planetary-labour-market-fairwork-cloudworkratings-2021/>

Galperin, H. and Alarcon, A. 2017. The Future of Work in the Global South. International Development Research Centre (IDRC), Ottawa.

Gitanjali, B. and Raveendran, R., 1998. Teaching research methodology to postgraduates: is dissertation the only method? National Medical Journal of India, 11, pp 23-24. 
Graham M., Woodcock J., Heeks, R., Mungai, P., Van Belle, J.P., du Toit, D., Fredman, S., Osiki, A., van der Spuy, A. and Silberman, S.M. 2020. The Fairwork foundation: strategies for improving platform work in a global context. Geoforum, 112, pp 100-103.

Heeks, R., Graham, M., Mungai, P., Van Belle, J.P. and Woodcock J., 2021. Systematic evaluation of gig work against decent work standards: The development and application of the Fairwork framework. The Information Society, pp 120. Available at: <https://doi.org/10.1080/01972243.2021.1942356> [Accessed 4 September 2021].

Heeks, R., 2017. Decent work and the digital gig economy: a developing country perspective on employment impacts and standards in online outsourcing, crowdwork, etc. Development Informatics Working Paper, (71).

Heeks R., Graham, M., Mungai, P., Van Belle, J.P. and Woodcock, J., 2020. Systematic Evaluation of Platform Work Against Decent Work Standards: Development of a New Framework and Application in the Global South. In Digital Development Working Papers Series, Paper 85, Available at: $<$ https://www.gdi.manchester.ac.uk/research/publications/di/di-wp85/> [Accessed 4 September 2021].

Howson, K., Katta, S., Graham, M., Van Belle, J.P, Heeks, R., du Toit, D., Fredman, F., Mungai, P., and Osiki, A., 2020. Fairwork South Africa: Ratings 2020: Labour Standards in the Gig Economy, Cape Town, South Africa, Oxford, United Kingdom, Available at: <https://fair.work/wp-content/uploads/sites/97/2020/04/Fairwork-South-Africa-2020report.pdf> [Accessed 4 September 2021].

Kent, M., Gilbertson, D. and Hunt, C., 1997. Fieldwork in geography teaching: a critical review of the literature and approaches. Journal of Geography in Higher Education, 21, pp 313-331.

Longmore, M.A., Dunn, D. and Jarboe, G.R., 1996. Learning by doing: Group projects in research methods classes. Teaching Sociology, 24(1), pp 84-91.

Lundahl, B.W., 2008. Teaching research methodology through active learning. Journal of Teaching in Social Work, 28(1-2), pp 273-288.

Panelli, R. and Welch, R.V., 2005. Teaching research through field studies: A cumulative opportunity for teaching methodology to human geography undergraduates. Journal of Geography in Higher Education, 29(2), pp 255-277.

Saeed, M.A. and Al Qunayeer, H.S., 2021. Can we engage postgraduates in active research methodology learning? Challenges, strategies and evaluation of learning. International Journal of Research \& Method in Education, 44(1), pp 3-19.

Schober, B., Wagner, P., Reimann, R., Atria, M. and Spiel, C., 2006. Teaching research methods in an internet-based blended-learning setting. Methodology, 2(2), pp.73-82.

Strangman, L., and Knowles, E., 2012. Improving the Development of Students' Research Questions and Hypotheses in an Introductory Business Research Methods Course. International Journal for the Scholarship of Teaching and Learning, 6, pp 1-13. Available at: <http://academics.georgiasouthern.edu/ijsotl/v6n2.html> [Accessed 4 September 2021].

Tashakkori, A. and Teddlie, C., 2003. Issues and dilemmas in teaching research methods courses in social and behavioural sciences: US perspective. International Journal of Social Research Methodology, 6(1), pp 61-77.

Wagner, C., Garner, M. and Kawulich, B., 2011. The State of the Art of Teaching Research Methods in the Social Sciences: Towards a Pedagogical Culture. Studies in Higher Education, 36(1), pp 75-88. doi:10.1080/03075070903452594.

Winn, S., 1995. Learning by doing: Teaching research methods through student participation in a commissioned research project. Studies in Higher Education, 20(2), pp 203-214. 